\title{
Structural aspects of fungal allergens
}

\author{
Crameri, Reto
}

\begin{abstract}
Despite the increasing number of solved crystal structures of allergens, the key question why some proteins are allergenic and the vast majority is not remains unanswered. The situation is not different for fungal allergens which cover a wide variety of proteins with different chemical properties and biological functions. They cover enzymes, cell wall, secreted, and intracellular proteins which, except cross-reactive allergens, does not show any evidence for structural similarities at least at the threedimensional level. However, from a diagnostic point of view, pure allergens biotechnologically produced by recombinant technology can provide us, in contrast to fungal extracts which are hardly producible as standardized reagents, with highly pure perfectly standardized diagnostic reagents.
\end{abstract}

DOI: https://doi.org/10.1007/s00281-014-0458-0

Posted at the Zurich Open Repository and Archive, University of Zurich

ZORA URL: https://doi.org/10.5167/uzh-119015

Journal Article

Published Version

Originally published at:

Crameri, Reto (2015). Structural aspects of fungal allergens. Seminars in Immunopathology, 37(2):117121.

DOI: https://doi.org/10.1007/s00281-014-0458-0 


\title{
Structural aspects of fungal allergens
}

\author{
Reto Crameri
}

Received: 9 July 2014 / Accepted: 4 November 2014 / Published online: 21 November 2014

(C) Springer-Verlag Berlin Heidelberg 2014

\begin{abstract}
Despite the increasing number of solved crystal structures of allergens, the key question why some proteins are allergenic and the vast majority is not remains unanswered. The situation is not different for fungal allergens which cover a wide variety of proteins with different chemical properties and biological functions. They cover enzymes, cell wall, secreted, and intracellular proteins which, except crossreactive allergens, does not show any evidence for structural similarities at least at the three-dimensional level. However, from a diagnostic point of view, pure allergens biotechnologically produced by recombinant technology can provide us, in contrast to fungal extracts which are hardly producible as standardized reagents, with highly pure perfectly standardized diagnostic reagents.
\end{abstract}

Keywords Fungi $\cdot$ Allergy $\cdot$ Allergens $\cdot$ Structures

\section{The kingdom of fungi and fungal allergens}

Among the over 100,000 fungal species reported [1], only a few hundred have been described as opportunistic pathogens [1] causing human illness through three specific mechanisms: direct infection of the host, elicitation of deregulated immune responses, and toxic effects due to secondary metabolites $[2$,

This article is a contribution to the special issue on Immunopathology of Fungal Diseases - Guest Editor: Jean-Paul Latge

R. Crameri

Swiss Institute of Allergy and Asthma Research (SIAF), University of Zürich, Davos, Switzerland

R. Crameri $(\bowtie)$

Department Molecular Allergology, Swiss Institute of Allergy and Asthma Research (SIAF), Obere Strasse 22, 7270 Davos, Switzerland

e-mail: crameri@siaf.uzh.ch
3]. Among these, about 80 mold genera have been shown to induce type I allergic reactions in atopic individuals [4]. The most important allergenic fungi belong to the genera Alternaria, Aspergillus, and Cladosporium [5], whereas members of the genera Candida, Penicillium, Clavularia, and other genus seem to be, with the exception of the genus Malassezia in patients suffering from atopic dermatitis [6, 7], less important as allergenic sources [8]. The host environment naturally restricts the number of fungi capable of inducing invasive fungi because only organisms surviving at $37{ }^{\circ} \mathrm{C}$ can grow and propagate into the host tissues. This might be different in the case of IgE sensitization caused by secreted allergens, fungal spores, and mycelium fragments which can be produced outside of the host at any temperature allowing fungal growth. It is interesting to note that the temperature-sensitive Aspergillus giganteus and Aspergillus restrictus which produce the ribotoxins mitogillin and restrictocin, respectively, later demonstrated to be practically identical to the major Aspergillus fumigatus allergen Asp f 1 [9], have never been reported as opportunistic fungal pathogens [10].

As pointed out in a recent review [11], although fungal allergens have been clearly associated with an array of pulmonary and skin diseases ranging from simple sensitization [12], allergic asthma [13] to life-threatening conditions like allergic bronchopulmonary aspergillosis [14], they have so far been largely neglected in the field of molecular allergology.

The number of fungal allergens currently officially recognized by the World Health Organization and International Union of Immunological Societies (WHO/IUIS) Allergen Nomenclature Sub-committee (www.allergen.org) is 84 for the genus Ascomycota and 23 for the genus Basidiomycota. However, the number of fungal proteins able to bind $\operatorname{IgE}$ described in the literature exceeds 200 allergens [4] and is far to be complete because the majority of the allergens described derives from the most important fungal species involved in pulmonary or skin diseases [15]. They are produced by the molds $A$. fumigatus with 
23, Alternaria alternata with 11, Cladosporium herbarum with eight described allergens involved in respiratory diseases [11], and to the yeast Malassezia sympodialis involved in skin diseases with ten described allergens [16]. Several of these allergens show cross-reactivity with homologous proteins found in other fungal species which has been clearly confirmed by experimental procedures and in many cases also in skin tests [17]. The most frequent cross-reactive fungal allergens are listed in Table 1.

\section{Solved three-dimensional structures of fungal allergens}

The first crystal structure of a fungal allergen solved was that of the ribotoxin restrictocin from $A$. restrictus [18] which is basically identical to the fungal allergen rAsp f 1 [10]. The ribotoxins disrupt the elongation factor binding and protein synthesis by specifically cleaving one phosphodiester bond in ribosomes resulting in apoptosis [19]. Although the mode of action of the ribotoxins has been elucidated in detail [20], it is unlikely that the enzymatic activity contributes to the allergenicity of the protein because enzymatically inactive mutants of Asp $f 1$ still retain the full allergenicity (R. Crameri, unpublished results). However, Asp f 1, the major allergen of A. fumigatus, is a highly specific marker for the $\operatorname{IgE}$ sensitization against the fungus even if close ortholog allergens might occur across the fungal kingdom [21].

Crystals and crystal structures of the allergens Asp f 6 [22], Mala s 6 [23], Mala s 13 [24], Asp f 11 [25], and Mala s 1 [26] are presented in Fig. 1. Except Mala s 1, all belong to the class of cross-reactive allergens which, notably, cross-react also to the homologous human proteins manganese superoxide dismutase, cyclophilin, and thioredoxin. This interesting phenomenon which could contribute to the perpetuation of the inflammatory response in chronic allergic diseases such as asthma,

Table 1 List of the most common cross-reactive fungal allergens

\begin{tabular}{|c|c|c|c|c|}
\hline Biochemical function & Allergen & MW (kDa) & Species & References \\
\hline Aldehyde dehydrogenase & $\begin{array}{l}\text { Alt a } 10 \\
\text { Cla h } 10\end{array}$ & $\begin{array}{l}53 \\
53\end{array}$ & $\begin{array}{l}\text { A. alternata } \\
\text { C. herbarum }\end{array}$ & $\begin{array}{l}{[48]} \\
{[48]}\end{array}$ \\
\hline Serine protease & $\begin{array}{l}\text { Asp fl } 13 \\
\text { Asap f } 13 \\
\text { Asp o } 13 \\
\text { Pen ch } 13 \\
\text { Pen c } 13\end{array}$ & 34 & $\begin{array}{l}\text { A flavus } \\
\text { A fumigatus } \\
\text { A Oryzae } \\
\text { P. chrysogenum } \\
\text { P. citrinum }\end{array}$ & $\begin{array}{l}{[49]} \\
{[49]} \\
{[49]} \\
{[49]} \\
{[49]}\end{array}$ \\
\hline Ribosomal P2 protein & $\begin{array}{l}\text { Alt a } 5 \\
\text { Asp f } 8 \\
\text { Cla h } 5 \\
\text { Fus c } 1\end{array}$ & $\begin{array}{l}11 \\
11 \\
11 \\
11\end{array}$ & $\begin{array}{l}\text { A. alternata } \\
\text { A. fumigatus } \\
\text { C. herbarum } \\
\text { F. Culmorum }\end{array}$ & $\begin{array}{l}{[48]} \\
{[50]} \\
{[48]} \\
{[51]}\end{array}$ \\
\hline Manganese superoxide dismutase & $\begin{array}{l}\text { Asp f } 6 \\
\text { Mala s } 11 \\
\text { Alt a } 14\end{array}$ & $\begin{array}{l}26.5 \\
23 \\
24\end{array}$ & $\begin{array}{l}\text { A. fumigatus } \\
\text { M. sympodialis } \\
\text { A. Alternata }\end{array}$ & $\begin{array}{l}{[22,28]} \\
{[27]} \\
{[52]}\end{array}$ \\
\hline Cyclophilin & $\begin{array}{l}\text { Asp f } 11 \\
\text { Asp f } 27 \\
\text { Mala s } 6 \\
\text { Psi c } 2\end{array}$ & $\begin{array}{l}24 \\
18 \\
17 \\
16\end{array}$ & $\begin{array}{l}\text { A. fumigatus } \\
\text { A. fumigatus } \\
\text { M. sympodialis } \\
\text { P. cubensis }\end{array}$ & $\begin{array}{l}{[25,34]} \\
{[23]} \\
{[23]} \\
{[53]}\end{array}$ \\
\hline Thioredoxin & $\begin{array}{l}\text { Asp f } 28 \\
\text { Asp f } 29 \\
\text { Fus c } 2 \\
\text { Cop c } 2 \\
\text { Mala s } 13\end{array}$ & $\begin{array}{l}13 \\
13 \\
13 \\
\mathrm{Nd} \\
13\end{array}$ & $\begin{array}{l}\text { A. fumigatus } \\
\text { A. fumigatus } \\
\text { F. culmorum } \\
\text { C. comatus } \\
\text { M. sympodialis }\end{array}$ & $\begin{array}{l}{[35]} \\
{[35]} \\
{[51]} \\
\text { [www.allergen.org] } \\
{[24]}\end{array}$ \\
\hline Peroxisomal protein & $\begin{array}{l}\text { Asp f } 3 \\
\text { Cand a } 3 \\
\text { Cand b } 2 \\
\text { Pen c } 3 \\
\text { Mala f } 2 \\
\text { Mala f } 3\end{array}$ & $\begin{array}{l}19 \\
20 \\
20 \\
18 \\
21 \\
20\end{array}$ & $\begin{array}{l}\text { A. fumigatus } \\
\text { C. albicans } \\
\text { C. boidinii } \\
\text { P. citrinum } \\
\text { M. furfur } \\
\text { M. furfur }\end{array}$ & $\begin{array}{l}{[54]} \\
{[w w w . a l l e r g e n . o r g]} \\
{[54]} \\
{[55]} \\
{[56]} \\
{[56]}\end{array}$ \\
\hline Enolase & $\begin{array}{l}\text { Alt a } 6 \\
\text { Asp f } 22 \\
\text { Cla h } 6 \\
\text { Cur } 12 \\
\text { Pen c } 22 \\
\text { Rho m } 2\end{array}$ & $\begin{array}{l}45 \\
46 \\
46 \\
48 \\
46 \\
\mathrm{Nd}\end{array}$ & $\begin{array}{l}\text { A. alternata } \\
\text { A. fumigatus } \\
\text { C. herbarum } \\
\text { C. lunata } \\
\text { P. citrinum } \\
\text { R. mucilaginosa }\end{array}$ & $\begin{array}{l}{[48]} \\
{[57]} \\
{[48]} \\
{[58]} \\
{[57]} \\
\text { [www.allergen.org] }\end{array}$ \\
\hline
\end{tabular}

$N d$ not described 

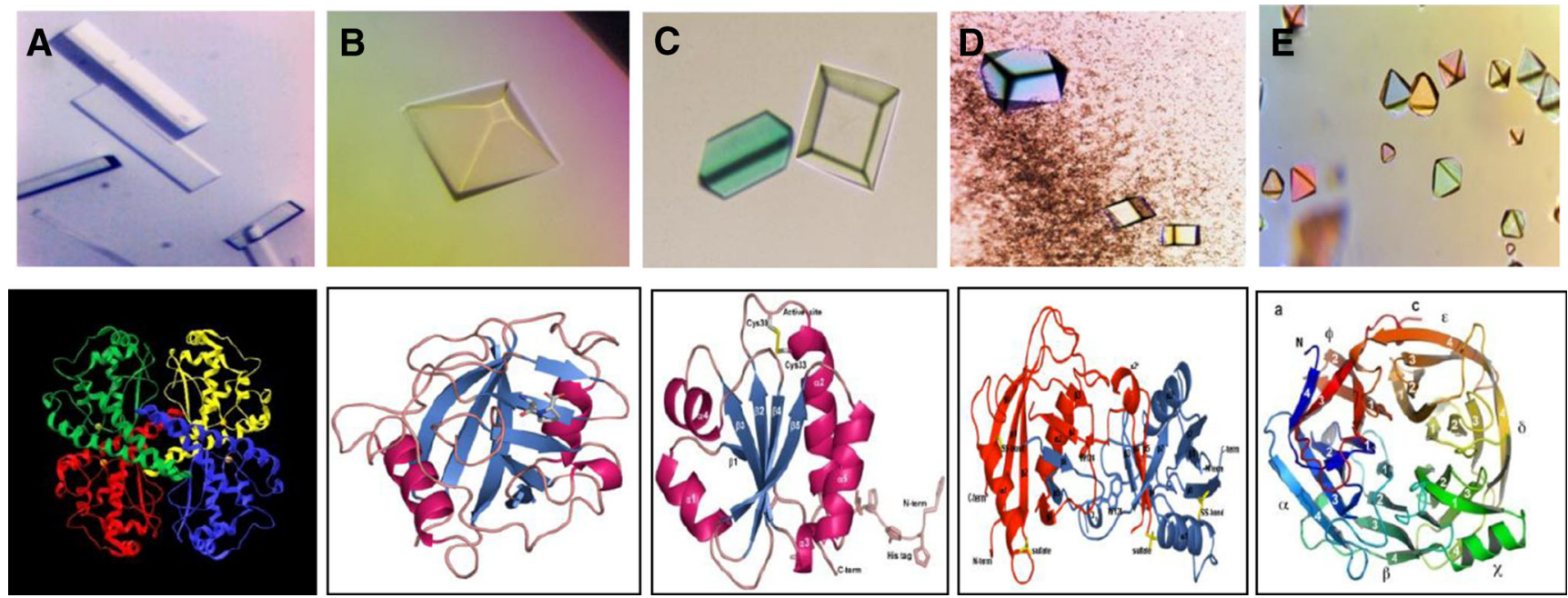

Fig. 1 Crystals and overall structures of a manganese superoxide dismutase from Aspergillus fumigatus (Asp f 6), b cyclophilin from Malassezia sympodialis (Mala s 6), c thioredoxin from Malassezia sympodialis (Mala s 13), d cyclophilin from Aspergillus fumigatus (Asp f 11), and e the major allergen Mala s 1 from Malassezia sympodialis allergic bronchopulmonary aspergillosis, and atopic dermatitis has been investigated in detail. Manganese superoxide dismutase has been shown to cross-react not only with the human homologous protein and allergens of other fungal species [27-32] but also with the corresponding enzymes of Escherichia coli and Drosophila melanogaster, the last one unlikely to be a source of exposure for human beings [33]. The overall structure of Asp $f 6$ forms a homotetramer in the crystal which is in agreement with the structures of manganese superoxide dismutases from other eukaryotic organisms [22], and therefore, it can be expected that manganese superoxide dismutases from many other fungi will cross-react with Asp $\mathrm{f} 6$.

In terms of allergenicity and cross-reactivity, similar results have been found for Mala s 6, the cyclophilin of $M$. sympodialis [23], and Asp f 11, the corresponding enzyme of A. fumigatus [25]. Also in this case. the fungal allergens are fully crossreactive with the homologous human proteins cyclophilins $\mathrm{A}$, $\mathrm{B}$, and $\mathrm{C}$ which share a high degree of sequence identity at amino acid level [24, 34]. However, in terms of the three-dimensional structure, marked differences can be observed. Like other cyclophilins, Mala s 6 shows an overall structure consisting of an eight-stranded antiparallel $\beta$-barrel and two $\alpha$-helices covering the top and bottom of the barrel all showing the same monomeric conformation [23]. In contrast, the crystal structure of Asp $\mathrm{f} 11$ reveals a three-dimensional domain swapping of a central element [25]. This is an intriguing situation because in general, cyclophilins are active in their monomeric form. Dimerization, as shown by the crystal structure, obviously inactivates the cis-trans isomerisation function, since both active sites are masked by their own swapped loops. In vitro, however, the Asp f 11 protein is clearly monomeric under physiological conditions and also shows cis-trans isomerisation activity [34] as expected for a functional enzyme. Therefore, dimerization of Asp f 11 in vivo could represent a mechanism for the downregulation of the enzymatic activity in absence of protein degradation. In terms of allergenicity, Asp f 11 is fully crossreactive with Mala s 6, Asp f 27, an additional cyclophilin of A. fumigatus showing a high degree of sequence identity with Asp f 11 , and with the human cyclophilins A, B, and C at amino acid sequence level [23, 34].

The crystal structure of the M. sympodialis thioredoxin (Mala s 13) shows a five-stranded $\beta$-sheet forming a hydrophobic core surrounded by five $\alpha$-helices typical for other thioredoxins [24]. The availability of the Mala s 13 crystal structure allowed using molecular homology modeling to identify conserved, surface-exposed amino acids potentially involved in immunoglobulin $\mathrm{E}$ binding and thus cross-reactivity [35]. Mala s 13 is extensively cross-reactive with Asp f 28, Asp f 29, and human thioredoxin. Notably, the gradual reduction of the total solvent-accessible surface area forming potential B cell epitopes between human thioredoxin, Asp f 28, Asp f 29, and Mala s 13 coincides with the $\operatorname{IgE}$ binding potential of the allergens [35]. The cross-reactivity between Mala s 13 and human thioredoxin has been also investigated in detail at $\mathrm{T}$ cell level [36]. Using ex vivo patient material from the skin and blood of patients suffering from atopic dermatitis sensitized to Mala s 13, it could be shown that Mala s 13-specific T lymphocytes are fully cross-reactive with human thioredoxin, irrespective of whether the $\mathrm{T}$ cell clones were derived from the blood or skin [36]. Therefore, thioredoxin-autoreactive skinhoming $\mathrm{T}$ cells might contribute through the secretion of proinflammatory cytokines such as IFN- $\gamma$, IL-17, and IL-22 to the pathogenesis of atopic eczema by perpetuating skin inflammation and chronification of atopic dermatitis [37].

A completely different situation emerged with the solution of the crystal structure of Mala s 1 [26]; the major allergen of M. sympodialis previously denoted Mala f 1 [38]. Mala s 1 lacks sequence similarity to any known protein, and as a 
consequence thereof also, the biological function of this allergen is fully unknown. As BLAST homology searches failed to reveal homology to known proteins allowing solving the structure by molecular replacement [39], the crystal structure of Mala s 1 was determined by single-wavelength anomalous dispersion technique using selenomethionine-substituted Mala s 1 protein [40]. The overall structure of Mala s 1 revealed a relatively compact cup-like $\beta$-propeller consisting of six blades, $\alpha, \beta, \chi, \delta, \varepsilon$, and $\Phi$, arranged cyclically around a central pore, a completely novel fold among allergens. However, a search for structural homologous to Mala s 1 using the program DALI [41] resulted in a number of significant hints, and four of the five top hints were sialidases. In deep analyses of the putative active side of Mala s 1, it revealed significant differences between Mala s 1 and the suggested homologs. Despite extensive investigations, an enzymatic function could assign to the protein. In terms of allergenicity, it has been shown that IgE-mediated sensitization to M. sympodialis allergens and also to Mala s 1 is highly specific for patients with atopic eczema [16] indicating a close relation between the yeast and the pathogenesis of the disease.

A further example of a unique allergen structure is Alt a 1, the major allergen of A. alternata [42]. Alternaria is one of the most common molds associated with allergic sensitization to fungi, and up to $80 \%$ of the patients sensitized to this fungus produce IgE antibodies to the major allergen Alt a 1. Natural Alt a 1 is a $30-k D a$ dimer composed of two separate subunits which migrates as two 16.4 and $15.3 \mathrm{kDa}$ bands under reducing conditions on SDS-PAGE gels, suggesting a disulfide bond linking the monomers [43]. The protein belongs to the class of highly species-specific fungal allergens, and in fact, very few Alt a 1 homologous structures have been found among the fungal kingdom [21]. A high-resolution X-ray crystal structure of recombinant Alt a 1 reveals that the allergen forms a unique, dimeric $\beta$-barrel structure [42], differing from all other structures currently reported in the Protein Data Bank [44] and defines a new protein family of homologous proteins exclusively found in molds. Although Alt a 1 has a classic, dimeric structure, the data do not necessarily support the hypothesis that dimerisation is an important prerequisite for allergenicity [45] as described before for Asp f 11, the cyclophilin of A. fumigatus which clearly binds IgE from the serum of sensitized patients in monomeric and dimeric forms [25].

\section{Concluding remarks}

Despite the prominent importance as allergenic sources [11], only few crystal structures of fungal allergens have been solved. However, the limited data available allows drawing firm conclusions. (i) As it is the case for all other allergens [46], also fungal allergens can be broadly assigned to crossreactive protein families and unique species-specific structures. Classical examples of cross-reactive (fungal) allergens are phylogenetically highly conserved proteins like thioredoxins, cyclophilins, ribosomal proteins, and other proteins essential for metabolic processes of the cells. Speciesspecific fungal allergens like the ribotoxins, Asp f 1, or the major allergens Mala 1 and Alt a 1 seem to be proteins which are not essential for the survival of the respective fungal species as demonstrated by knockout experiments [47]. (ii) The solved structures of Mala s 1 and Alt a 1 provide examples of unique allergen folds, indicating that the potential of an allergen to induce a switch towards allergen-specific $\operatorname{IgE}$ production is unlikely to be directly related to common structural folds. (iii) Although the determination of crystal structures of many allergens failed to deliver an explanation for the allergenic potential of the proteins, they provided us with perfectly standardized diagnostic reagents with, perhaps, also a potential for the development of novel therapeutic concepts for the treatment of IgE-mediated allergic diseases.

Acknowledgments The laboratory of the author is supported by the Swiss National Science Foundation grant nos. 320030149978 and 31NM30_152038/1 (EuroNanoMed) and by the European Community's Seventh Framework Program [FP7-2007-2013] under grant agreement no. HEALTH-F2-2010-260338 “ALLFUN."

Conflict of interest Author declares no conflict of interest.

\section{References}

1. Prillinger $\mathrm{H}$ et al (2002) Phylogeny and systematics of the fungi with special reference to the Ascomycota and Basidiomycota. Chem Immunol 81:207-295

2. Horner WE, Helbling A, Salvaggio EJ, Lehrer SB (1995) Fungal allergens. Clin Microbiol Rev 8:8161-8179

3. Bush RK, Portneoy JA, Saxon A, Terr AI, Wood RA (2006) The medical effects of mold exposure. J Allergy Clin Immunol 117:326333

4. Simon-Nobbe B, Denk U, Pöll V, Rid R, Breitenbach M (2008) The spectrum of fungal allergy. Int Arch Allergy Immunol 145:58-86

5. Crameri R, Weichel M, Flückiger S, Glaser AG, Rhyner C (2006) Fungal allergies: a yet unsolved problem. Chem Immunol Allergy 91:121-133

6. Gaitanis G et al (2012) The Malassezia genus in skin and systemic diseases. Clinic Microbiol Rev 25:106-141

7. Schmid-Grendelmeier P, Scheynius A, Crameri R (2006) The role of sensitization to Malassezia sympodialis in atopic eczema. Chem Immunol Allergy 91:98-109

8. Mari A, Schneider P, Wally V, Breitenbach M, Simon-Nobbe B (2003) Sensitization to fungi: epidemiology, comparative skin tests, and IgE reactivity of fungal extracts. Clin Exp Allergy 33:1429-1438

9. Kao R, Martínez-Ruiz A, Martínez del Pozo A, Crameri R, Davies J (2001) Mitogillin and related fungal ribotoxins. Meth Enzymol 341: 324-335

10. Moser $\mathrm{M}$ et al (1992) Cloning and expression of recombinant Aspergillus fumigatus allergenI/a (rAsp f I/a) with IgE binding and type I skin test activity. J Immunol 149:454-460

11. Crameri R, Garbani M, Rhyner C, Huitema C (2014) Fungi: the neglected allergenic sources. Allergy 69:176-185 
12. Kurup VP (2003) Fungal allergy. In: Arora N (ed) Handbook of fungal biotechnology. Dekker, New York, pp 515-525

13. Agarwal R (2011) Severe asthma with fungal sensitization. Curr Allergy Asthma Rep 11:403-413

14. Patterson K, Strek ME (2010) Allergic bronchopulmonary aspergillosis. Proc Am Thor Soc 7:237-244

15. Fraczek MG, Bowyer $P$ (2013) Genomics of fungal allergens. Fungal Genom Biol 3:e114. doi:10.4172/2165-8056.1000e114

16. Casagrande B et al (2006) Sensitization to the yeast Malassezia sympodialis is specific for extrinsic and intrinsic eczema. J Invest Dermatol 126:2414-2421

17. Zeller S, Glaser AG, Vilhelmsson M, Rhyner C, Crameri R (2009) Cross-reactivity among fungal allergens: a clinically relevant phenomenon? Mycoses 52:99-106

18. Yang X, Moffat K (1996) Insights into specificity of cleavage and mechanism of cell entry from the crystal structure of the highly specific Aspergillus ribotoxins, restrictocin. Structure 15:837-852

19. Olmo $\mathrm{N}$ et al (2001) Cytotoxic mechanism of the ribotoxins alpha-sarcin. Induction of cell death via apoptosis. Eur J Biochem 268:2113-2123

20. Yang X, Gérczei T, Glover LT, Correll CC (2001) Crystal structure of restrictocin-inhibitor complexes with implication for RNA recognition and base flipping. Nature Struct Biol 8:968-973

21. Bowyer P, Fraczek M, Denning DW (2006) Comparative genomics of fungal allergens and epitopes shows widespread distribution of closely related allergen and epitope orthologues. BMC Genomics 7:251

22. Flückiger $S$ et al (2002) Comparison of the crystal structures of the human manganese superoxide dismutase and the homologous Aspergillus fumigatus allergen at 2-Å resolution. J Immunol 168:1267-1272

23. Glaser AG et al (2006) Analysis of the cross-reactivity and of the 1.5 A structure of the Malassezia sympodialis Mala s 6 allergen, a member of the cyclophilin pan-allergen family. Biochem $\mathrm{J}$ 396:41-49

24. Limacher A et al (2007) Cross-reactivity and 1.4- $\AA$ crystal structure of Malassezia sympodialis thioredoxin (Mala s 13), a member of a new pan-allergen family. J Immunol 178:389-396

25. Limacher A et al (2006) The crystal structure of Aspergillus fumigatus cyclophilin reveals $3 \mathrm{D}$ domain swapping of a central element. Structure 14:185-195

26. Vilhelmsson M et al (2007) Crystal structure of the major Malassezia sympodialis allergen Mala s 1 reveals a beta-propeller fold: a novel fold among allergens. J Mol Biol 369:1079-1086

27. Vilhelmsson M et al (2008) Mutational analysis of amino acid residues involved in IgE-binding to the Malassezia sympodialis allergen Mala s 11. Mol Immunol 46:294-303

28. Flückiger $S$ et al (2002) Immunological and structural analysis of IgE-mediated cross-reactivity between manganese superoxide dismutases. Int Arch Allergy Immunol 128:292-303

29. Schmid-Grendelmeier P et al (2005) IgE-mediated and T cellmediated autoimmunity against manganese superoxide dismutase in atopic dermatitis. J Allergy Clin Immunol 115:1068-1075

30. Vilhelmsson M et al (2007) The Malassezia sympodialis allergen Mala s 11 induces human dendritic cell maturation, in contrast to its human homologue manganese superoxide dismutase. Int Arch Allergy Immunol 143:155-162

31. Crameri R (1996) Humoral and cell-mediated autoimmunity in allergy to Aspergillus fumigatus. J Exp Med 184:265-270

32. Appenzeller U, Meyer C, Menz G, Blaser K (1999) IgE-mediated reactions to autoantigens in allergic diseases. Int Arch Allergy Immunol 118:193-196

33. Mayer C, Hemmann S, Faith A, Blaser K, Crameri R (1997) Cloning, production, characterization and IgE cross-reactivity of different manganese superoxide dismutases in individuals sensitized to Aspergillus fumigatus. Int Arch Allergy Immunol 113:213-215

34. Flückiger S, Fijten H, Whitley P, Blaser K, Crameri R (2002) Cyclophilins, a new family of cross-reactive allergens. Eur J Immunol 32:10-17
35. Glaser AG et al (2008) Auto- and cross-reactivity to thioredoxin allergens in allergic bronchopulmonary aspergillosis. Allergy 63: $1617-1623$

36. Balaji $\mathrm{H}$ et al (2011) Malassezia sympodialis thioredoxin-specific $\mathrm{T}$ cells are highly cross-reactive to human thioredoxin in atopic dermatitis. J Allergy Clin Immunol 128:92-99.e4

37. Eyerich K et al (2009) IL-17 in atopic eczema: linking allergenspecific adaptive and microbial-triggered innate immune response. $\mathrm{J}$ Allergy Clin Immunol 123:59-66

38. Schmidt M et al (1997) The complete cDNA sequence and expression of the first major allergenic protein of Malassezia furfur, Mal $\mathrm{f} 1$. Eur J Biochem 246:181-185

39. Vagin A, Teplyakow A (1997) MOLREP: an automated program for molecular replacement. J Appl Crystallogr 30:1022-1025

40. Schneider TR, Sheldrick GM (2002) Substructure solution with SHELXD. Acta Crystallog Sec D 58:1772-1779

41. Holm L, Sander C (1998) Touring protein fold space with Dali/FSSP Nucleic Acids Res 32:D217-D222

42. Chruszecz $M$ et al (2012) Alternaria alternata allergen Alt a 1: a unique $\beta$-barrel protein dimer found exclusively in fungi. J Allergy Clin Immunol 130:241-247

43. Deards MJ, Montague AE (1991) Purification and characterisation of a major allergen of Alternaria alternata. Mol Immunol 28:409-415

44. Berman HM et al (2000) The Protein Data Bank. Nucleic Acids Res 28:235-242

45. Rouvinen J, Janis J, Laukkanen ML et al (2010) Transient dimmers of allergens. PLoS One 5:e9037

46. Radauer $\mathrm{C}$ et al (2014) Update of the WHA/IUIS allergen nomenclature database based on analysis of allergen sequences. Allergy 69 : 413-419

47. Paris $\mathrm{S}$ et al (1993) A transformant of Aspergillus fumigatus deficient in the antigenic cytotoxin ASPF1. FEMS Microbiol Lett 111:31-36

48. Achatz G et al (1995) Molecular cloning of major and minor allergens of Alternaria alternata and Cladosporium herbarum. Mol Immunol 32:213-227

49. Shen HD, Tam MF, Chou H, Han SH (1999) The importance of serine proteinases as aeroallergens associated with asthma. Int Arch Allergy Immunol 119:259-264

50. Mayer C et al (1999) Humoral and cell-mediated autoimmune reactions to human acidic ribosomal $\mathrm{P}_{2}$ protein in individuals sensitized to Aspergillus fumigatus $\mathrm{P}_{2}$ protein. J Exp Med 189:1507-1512

51. Hoff $\mathrm{M}$ et al (2003) Molecular cloning and immunological characterisation of potential allergens from the mould Fusarium culmorum. Mol Immunol 39:965-975

52. Postigo I et al (2011) Diagnostic value of Alt a 1, fungal enolase and manganese-dependent superoxide dismutase in the componentresolved diagnosis of allergy to Pleosporaceae. Clin Exp Allergy 41:443-451

53. Helbling A, Horner WE, Lehrer SB (1993) Identification of Psilocybe cubensis spore allergens by immunoprinting. Int Arch Allergy Immunol 100:263-267

54. Hemmann S, Blaser K, Crameri R (1997) Allergens of Aspergillus fumigatus and Candida boidinii share IgE-binding epitopes. Am J Respir Crit Care Med 156:1956-1962

55. Shen HD et al (2000) Complementary DAN cloning and immunologic characterization of a new Penicillium citrinum allergen (Pen c 3). J Allergy Clin Immunol 105:827-833

56. Yasueda $\mathrm{H}$ et al (1998) Identification and cloning of two novel allergens from the lipophilic yeast, Malassezia furfur. Biochim Biophys Res Comm 248:240-244

57. Lai HY et al (2002) cDNA cloning and immunological characterization of a newly identified enolase allergen from Penicillium citrinum and Aspergillus fumigatus. Int Arch Allergy Immunol 127:181-190

58. Sharma V et al (2006) Cloning, recombinant expression and activity studies of a major allergen "enolase" from the fungus Curvularia lunata. J Clin Immunol 26:360-369 